\title{
Sepp - Mathematics as a Viable Feeder Program into B.Sc Mathematics-Education at the University Of Lagos
}

\author{
${ }^{1}$ A.O. Okunuga, ${ }^{2}$ Comfort O Reju, ${ }^{3}$ M. O. Akintayo, \\ ${ }^{1}$ Head, Science-Education Programme Distance Learning Institute University of Lagos Lagos, Nigeria \\ ${ }^{2}$ Lecturer, DLI University of Lagos Akoka, Lagos, Nigeria \\ ${ }^{3}$ Professor \& Head of Department, Department of Adult Education, Faculty of Education University of Ibadan \\ Oyo State, Nigeria
}

\begin{abstract}
The British colonial masters in Nigeria did not encourage the teaching of science in the schools. At best science was taught as Nature Study and General Science. There was also shortage of middle-level manpower besides the gross shortage of qualified science teachers. To combat the acute shortage of qualified science teachers in Nigeria the Special Entry Preparatory programme (SEPP) was instituted in the University of Lagos to absorb and upgrade the unqualified science teachers to the level of graduate science teachers with education background. The SEPP students were brought up to the advance level of General Certificate in Education $(G C E A / L)$ which was the required qualification for direct admission into the university. Mathematics was one of the science-education courses taught through distance learning for a B.Sc degree. Using the Mann-Whitney test the performance of successful SEPP students was compared with those of "direct" students in the six courses offered. The two groups performed at the same level in four courses while outdoing each other in each of the remaining two courses.
\end{abstract}

Key Words: Distance Education, Special Entry Preparatory Programme (SEPP), Direct Entry.

\section{Introduction}

Many students view mathematics as a difficult subject and with great trepidation (Olatoye, 2007). Hence there is mass failure in the subject at local, national and international examinations such as the West African School Certificate Examination (WASC) and the General Certificate of Education (GCE) examinations and the Junior Secondary School (JSS) examinations. Poor performance at these examinations has prevented thousands of students from gaining admissions into tertiary institutions where credit passes at WASC and GCE are required.

The fear of Mathematics also makes many students shy away from the sciences. Many topics in science subjects cannot be understood without sound knowledge of Mathematics (Odousoro, 2000). Mathematics is a fundamental science which is necessary for the understanding of most other fields (Setidisho, 1996). Mathematics is also the language of science and central intellectual discipline (Kalejaiye, 1985 and Odeyemi, 1995). Hence, for any country to achieve great height in science and technology, the teaching of Mathematics must have priority clearance in its schools.

Besides students' trepidation at Mathematics is another major factor that predicates poor performance in the quality of teachers that teach Mathematics in schools. At independence there was a preponderance of unqualified teachers especially in our primary and secondary schools. Most of the teachers were holders of Teachers' Certificate Grade Two (TCII); this was the caliber of teachers who taught Mathematics and the sciences (general science). Most of the teachers were themselves petrified of the subject, having no in-depth knowledge or feelings for it and thus passing the traits to their pupils.

In addressing this problem of shortage of adequate manpower in general and teachers in particular the government of the newly independent Nigeria instituted the Ashby Commission to recommend ways to overcome this debate. The Commission recommended the establishment of tertiary institutions in major towns in each of the existing regions of the country. Thus, in addition to the only university at that time (i.e. the University College of Ibadan (UCI) now the University of Ibadan (UI)), other universities were established in Zaria (Ahmadu Bello University, ABU), Nsukka (University of Nigeria, Nsukka UNN) and Lagos (the University of Lagos, UNILAG).

\section{Distance Learning and Mathematics - Teachers' Education}

Because of the cosmopolitan nature of Lagos, the University of Lagos was designed to, in addition to formal education, engage in distance education to give "second chance" to those who, for one reason or the other could not undergo formal tertiary education. 
Emphasis was placed on the training of teachers in the sciences. And so, with the founding of the Correspondence and Open Studies Unit (COSU) in the 1973/74 session, Science-Education had a pivot start besides Business Administration and Accounting. The courses were for a B.Sc degree in Biology-Education, Chemistry-Education, Physics-Education and Mathematics-Education. There was also a Postgraduate Diploma in Education course for graduates who had no teaching experience. COSU has since transformed through the Correspondence and Open Studies Institute (COSIT) in 1983 to the present Distance Learning Institute (DLI) in 1995.

Admission of students into COSU commenced in 1976 with an intake of 501. At that time the Advance Level of the General Certificate of Education (GCE A/L) or the Higher School Certificate (HSC) was required for admission into the university. However, a Preliminary Programme (Prelim) in the full-time mode served to admit brilliant students with high scores in WASC or GCE ordinary level (GCE O/L). In the full-time those who came in with GCE A/L or HSC spent a minimum of three years while those admitted through the Prelim spent a minimum of four years; the former was called "direct" admission.

The same criteria were applied in admitting students into the COSU Science-Education programmes with those holders of GCE A/L and Higher National Diploma (HND) and Higher School Certificate (HSC), being admitted into a "direct" five-year study programme. Those with WASC or GCE O/L were admitted into a one-year preliminary programme called the Special Entry Preparatory Programme (SEPP). To accommodate TCII teachers, a two-year SEPP was put in place; also admitted into this group were teachers with Associate Certificate in Education (ACE) who had been taught Mathematics and Science, these had become headteachers in primary schools who desired university education.

\section{Literature Review}

Predicting students' performance in an academic programme is a useful but difficult and challenging undertaking as it is a product of various factors, e.g. psychological, socio-economic, environmental, age, gender and prior academic and/or experimental qualification (Affendey et al, 2010, Patricia, 2006; Syed and Raza, 2006; Yoonna and Soyibo, 2001). Most institutions of higher learning store up students' information as database which forms useful extractable knowledge. These data can be used by the institution's Curriculum Committees in predicting results to guide changes in the curricula and evaluate the effects of those changes. Prediction results obtained from such database can be referred to by an academic course adviser in giving advice to students who perform weakly in their studies so that preemptive measures can be taken earlier to forestall dropping out (Affendey, et al, 2010).

In addition, an instructor can make adjustment and improvement to his/her teaching and learning approach and also plan intervention and support services for weak students. According to Golding and Donaldson (2006) first year courses are possible factors that determine academic performance. Identifying the attributes that contribute the most significantly to students' academic performance can help to improve the intervention strategies and support services for students who perform poorly in their studies at an earlier stage.

A few recent studies show that the priority of science is declining both at the school and university levels whereas enrolment in economics is increasing over the last decade (Kumer, et al, 2008). There is especially poorer performance in Mathematics which is the main factor for the decline in the sciences.

The most significant predictors and those which have direct influence on student academic performance include age (Blackman et al, 2004; Aldous et al, 1999; Hugg and Fang, 1999; Kay, Person and Rolfe, 2002; Rolfe, Person, Powis and Smith, 1995; and James and Chilvers, 2001), gender (Kim and Lee, 2007), and prior academic achievement (Kooi and Ping, 2007; Blackman and Darmawan, 2004; Graig et al, 2004).

Kooi and Ping (2007) ascertained that the combined factor of academic background and age have very little significant effect on academic performance indexed by Grade Point Average (GPA). However, independently each is capable of affecting a student's academic performance. Jossey (1997) retreated that GPA has been regarded as a numerical criterion of academic performance.

Chansarkar and Mishaeloudis (2001) were of the opinion that age does not affect students' performance, but prior academic qualification is associated with performance of quantitative subjects. Kooi and Ping (2007) stated that the educational background of a student can positively predict the GPA performance where students with higher academic qualifications tend to have higher GPA. Craig et al (2004) also declared that prior subject area of academic qualification affect academic performance. Woodfield et al (2005) found that entry qualifications (measured according to A-level points) are significant determinants of academic achievement while Gracia and Jenkins (2003) noted that relevant work experience enhances academic performance. 


\section{THE SEPP MATHEMATICS COURSES}

The courses taught in the SEPP-Mathematics prograrmme were:

\begin{tabular}{|c|l|c|}
\hline Course Code & \multicolumn{1}{|c|}{ Course Name } & Unit \\
\hline MAT 021 & Pure Mathematics I & 2C \\
\hline MAT 022 & Pure Mathematics II & 2C \\
\hline MAT 023 & Pure Mathematics III & 2C \\
\hline MAT 024 & Applied Mathematics I & 2C \\
\hline MAT 025 & Applied Mathematics II & 2C \\
\hline MAT 026 & Applied Mathematics III & 2C \\
\hline
\end{tabular}

Successful students must have an average mark of $40 \%$ in each of Pure Mathematics and Applied Mathematics courses to proceed to the "direct" class and mix with new entrance who had been admitted with GCE A/L, NCE or HND.

The SEPP prepared the students to the level of General Certificate of Education A/L) (GCE A/L), the National Certificate of Education (NCE) or the Higher National Diploma (HND) standard and usher successful students into the five-year "direct" level. It was presumed that upon passing the SEPP courses the SEPP student would be at par with the holders of GCE A/L, NCE or HND who were admitted directly into Year 2/Part IA.

This study examines the effectiveness of the SEPP-Mathematics as a feeder into the B.Sc-EducationMathematics programme through distance learning in the old COSU/COSIT of the University of Lagos. Though the SEPP was scrapped in the 1989/90 academic session, a study of its effectiveness is imperative as it would be an eye-opener to those who would want to set up such a feeder programme.

\section{Method Of Analysis}

In the Year 2/Part IA class, the "direct" and upgraded SEPP students merge. The courses taken by them were:

\section{Year 2/Part IA Courses}

\begin{tabular}{|c|l|c|}
\hline Course Code & \multicolumn{1}{|c|}{ Course Name } & Unit \\
\hline MAT 101 & Analysis I & $2 \mathrm{C}$ \\
\hline MAT 103 & Algebra I & $2 \mathrm{C}$ \\
\hline MAT 106 & Differential Equation & $1 \mathrm{C}$ \\
\hline EDA 101 & History of Education & $2 \mathrm{C}$ \\
\hline EDF 122 & Educational psychology & $2 \mathrm{C}$ \\
\hline GAS 201/202 & General African Studies I \& II & $2 \mathrm{R}$ \\
\hline
\end{tabular}

Note: $\mathbf{C}=$ Compulsory; $\mathbf{R}=$ University required courses.

Records of performance of the two groups of students were obtained from the Distance Learning Institute's (DLI's) Record Office. The grades were weighted thus:

$90-100-6$

$70-89-5$

$60-69-4$

$50-59-3$

$40-49-2$

$35-39-1$

$0-34-0$

The Mann-Whitney non-parametric test was used in comparing the performance of the "direct" and SEPP students. The two samples/groups were first combined and then ranked, keeping trace of the group to which each observation belong (Okafor, 2004).

Letting $S_{\text {in }}$ be the sum of the ranks assigned to the SEPP samples and $S_{n}$ to the "direct" entry (DR) group; then the SEPP sample being of the size $m$, while the DR is of size $n$

$\mathrm{T}_{\mathrm{m}}=\mathrm{S}_{\mathrm{m}}-\underline{\mathrm{m}(\mathrm{m}+1)}$

$\mathrm{T}_{\mathrm{n}}=\mathrm{S}_{\mathrm{n}}-\underline{\mathrm{n}(\mathrm{n}+1)}$

We can use $T_{m}$ or $T_{n}$ to test the hypothesis 
$H_{\mathrm{o}}: \mathrm{M}_{\mathrm{m}} \equiv \mathrm{M}_{\mathrm{n}}$ (i.e. SEPP students perform equally as well as DR students)

$H_{1}: M_{m}<M_{n}$ (i.e. SEPP students perform lower than DR Students).

Where $\mathrm{M}_{\mathrm{m}}$ the median of the sample of size $\mathrm{m}$, and $\mathrm{Mm}$ is is the median of the sample of size $n$.

Then, $\mathrm{T}_{\mathrm{m}} \sim \mathrm{N} \underline{\mathrm{mn}}\left(\frac{\mathrm{mn}(\mathrm{m}+1)}{2} 12\right)$

That is, Tm has asymptomatic normal distribution with mean $\underline{\mathrm{mn}}$, and variance $\underline{\mathrm{mn}(\mathrm{m}+\mathrm{n}+1)}$

12

The data were subjected to the Statistical Package for Social Sciences (SPSS 15) at $p>0.05$. If the calculated $p$ value of the test is less than 0.05 , we reject $\mathrm{H}_{0}$. The rejection of Ho means that one group performed better than the other and the sum of the ranks will indicate the group that performed better.

\section{Results}

Table 1 (A \& B) shows the Mann-Whitney test results on the performance of SEPP and DR students in MAT 101. The p-value of 0.057 being greater than 0.05 means that there is no significant difference in the two groups. Hence the SEPP group performed as well as the DR group in MAT 101.

Table 1: Mann-Whitney results of student's performance in MAT 101

\begin{tabular}{|l|l|l|l|l|}
\hline \multicolumn{1}{|c|}{ LA } & \multicolumn{1}{c|}{ N } & \multicolumn{1}{c|}{ Mean Rank } & Sum of Ranks \\
\hline VA & SEPP Performance in MAT 101 & 94 & 135.14 & 12703.50 \\
\hline & DR Performance in MAT 101 & 202 & 154.72 & 31252.50 \\
\hline & Total & 296 & & \\
\hline
\end{tabular}

Test Statistics ${ }^{\mathbf{a}}$

a Grouping Variable: LA

\begin{tabular}{|l|l|}
\hline & \multicolumn{1}{c|}{ VA } \\
\hline Mann-Whitney U & 8288.500 \\
\hline Wilcoxon W & 1203.500 \\
\hline Z & $-1,907$ \\
\hline Asymp. Sig. (2-tailed) & .057 \\
\hline
\end{tabular}

Table 2 shows the result of the groups' performance in MAT 106. The p-value of 0.72 being greater than 0.05 shows there is no significant difference in the performances of the SEPP and DR groups. However, a look at the Mean Rank shows the SEPP's 148.72 being higher than that of the DR of 129.98; this shows a somewhat slight higher performance of the SEPP group.

Table 2: Performance of SEPP and DR groups in MAT 106

\begin{tabular}{|l|l|r|r|l|}
\hline \multicolumn{2}{|c|}{ LA } & N & \multicolumn{1}{c|}{ Mean Rank } & Sum of Ranks \\
\hline VA & SEPP Performance in MAT 106 & 72 & 148.72 & 10708.50 \\
\hline & DR Performance in MAT 106 & 197 & 129.98 & 25607.00 \\
\hline & Total & 269 & & \\
\hline
\end{tabular}

Test Statistics $^{\mathbf{a}}$

a Grouping Variable: LA

\begin{tabular}{|l|r|}
\hline & \multicolumn{1}{|c|}{ VA } \\
\hline Mann-Whitney U & 6104.000 \\
\hline Wilcoxon W & 25607.000 \\
\hline Z & -1.801 \\
\hline Asymp. Sig. (2-tailed) & .072 \\
\hline
\end{tabular}

The result of the analysis of performance of the two groups in MAT 103 shows a p-value of 0.003 which, being less than 0.05 indicates a significant difference in performance of the two groups. The Mean Rank of the DR 
(148.83) which is greater than that of the SEPP (119.02) means that the DR performed better than the SEPP group (SEPP < DR in MAT 103).

Table 3: Mann-Whitney test result of performance in MAT 103

\begin{tabular}{|l|l|r|r|l|}
\hline \multicolumn{2}{|c|}{ LA } & \multicolumn{1}{c|}{ N } & \multicolumn{1}{c|}{ Mean Rank } & \multicolumn{1}{c|}{ Sum of Ranks } \\
\hline VA & SEPP Performance in MAT 106 & 87 & 119.02 & 10354.50 \\
\hline & DR Performance in MAT 106 & 191 & 148.83 & 28426.50 \\
\hline & Total & 278 & & \\
\hline
\end{tabular}

Test Statistics ${ }^{\mathbf{a}}$

a Grouping Variable: LA

\begin{tabular}{|l|r|}
\hline & \multicolumn{1}{|c|}{ VA } \\
\hline Mann-Whitney U & 6526.500 \\
\hline Wilcoxon W & 10354.500 \\
\hline Z & -2.960 \\
\hline Asymp. Sig. (2-tailed) & .003 \\
\hline
\end{tabular}

Analysis of the performance of the two groups in EDA 101 gives a p-value of 0.104 which is higher than 0.05 . This means that there is no significant difference in the performance of the SEPP and DR groups (SEPP $\equiv$ DR).

Table 4: Analysis of performance in EDA 101

\begin{tabular}{|l|l|r|r|l|}
\hline \multicolumn{2}{|c|}{ LA } & N & \multicolumn{1}{c|}{ Mean Rank } & Sum of Ranks \\
\hline VA & SEPP Performance in EDA 101 & 86 & 143.09 & 12306.00 \\
\hline & DR Performance in EDA 101 & 224 & 160.26 & 35899.00 \\
\hline & Total & 310 & & \\
\hline
\end{tabular}

Test Statistics ${ }^{\mathbf{a}}$

a Grouping Variable: LA

\begin{tabular}{|l|r|}
\hline & \multicolumn{1}{|c|}{ VA } \\
\hline Mann-Whitney U & 8565.000 \\
\hline Wilcoxon W & 12306.000 \\
\hline Z & -1.624 \\
\hline Asymp. Sig. (2-tailed) & .104 \\
\hline
\end{tabular}

Table 5 shows Mann-Whitney test analysis of performance in EDF 122 . The p-value of 0.765 being greater than 0.05 indicates that there is no significant differences in the performance of the SEPP and DR Groups.

Table 5: Mann-Whitney test results of performance in EDF 122

\begin{tabular}{|l|l|r|r|l|}
\hline \multicolumn{2}{|c|}{ LA } & \multicolumn{1}{c|}{ N } & \multicolumn{1}{c|}{ Mean Rank } & \multicolumn{1}{c|}{ Sum of Ranks } \\
\hline VA & SEPP Performance in MAT 106 & 97 & 153.43 & 14882.50 \\
\hline & DR Performance in MAT 106 & 213 & 156.44 & 33322.50 \\
\hline & Total & 310 & & \\
\hline
\end{tabular}

Test Statistics ${ }^{\mathbf{a}}$

a Grouping Variable: LA

\begin{tabular}{|l|r|}
\hline & \multicolumn{1}{|c|}{ VA } \\
\hline Mann-Whitney U & 10129.500 \\
\hline Wilcoxon W & 14882.500 \\
\hline Z & -.299 \\
\hline Asymp. Sig. (2-tailed) & .765 \\
\hline
\end{tabular}

In the analysis of performance of the two groups in General African Studies a p-value of 0.00 was recorded. Since this is lower than 0.05 , it shows that there is a significant difference in the performances of the SEPP and the DR groups. A look at the Mean Rank shows the SEPP group with a higher value (49.16) than the DR group. This shows that the SEPP group performed better in GAS 101/102. 
Table 6: Analysis of performance in GAS 101.102

\begin{tabular}{|l|l|c|c|c|}
\hline & LA_EDM_GAS_101_102 & N & Mean Rank & Sum of Ranks \\
\hline $\begin{array}{l}\text { VA_EDM_GAS } \\
\text { 101_102 }\end{array}$ & $\begin{array}{l}\text { Performance of SEPP } \\
\text { Maths in GAS 101/102 }\end{array}$ & 19 & 49.16 & 934.00 \\
\hline & $\begin{array}{l}\text { Performance of DR } \\
\text { Maths in GAS 101/102 }\end{array}$ & 45 & 25.47 & 1146.00 \\
\hline & Total & 64 & & \\
\hline
\end{tabular}

Test Statistics $^{\mathrm{a}}$

\begin{tabular}{|l|r|}
\hline & $\begin{array}{r}\text { VA_EDM_GAS } \\
\text { 101_102101 }\end{array}$ \\
\hline Mann-Whitney U & 111.000 \\
\hline Wilcoxon W & 1146.000 \\
\hline Z & -4.939 \\
\hline Asymp. Sig. (2-tailed) & .000 \\
\hline
\end{tabular}

SUMMARY

Table 7: Summary of Mann-Whitney tests on performances of SEPP and DR students in EducationMathematics Courses

\begin{tabular}{|c|c|c|}
\hline Course Code & @ p. 0.05 & Group Performance \\
\hline MAT 101 & 0.057 & SEPP $\equiv$ DR \\
\hline MAT 103 & 0.003 & SEPP < DR \\
\hline MAT 106 & 0.072 & SEPP $\equiv$ DR \\
\hline EDA 101 & 0.104 & SEPP $\equiv$ DR \\
\hline EDF 122 & 0.765 & SEPP $\equiv D R$ \\
\hline GAS 201/202 & 0.000 & SEPP $>$ DR \\
\hline
\end{tabular}

Table 7 reveals that the DR group outperformed the SEPP group in only one course, MAT 103, while the SEPP outperformed the DR group in GAS 101/102. The SEPP and DR groups performed at the same level in four of the six courses vis MAT 101, 106, EDA 101 and EDF 122.

\section{Conclusion}

The result of the findings shows that the SEPP performed as well as the DR group in four of the six courses, outperformed the DR group in one and was outperformed in only one course. This points to the effectiveness of the SEPP as a good feeder programme into the B.Sc Mathematics-Education programme of the old Correspondence and Open Studies Unit (COSU), later Correspondence and Open Studies Institute (COSIT) which is now the Distance Learning Institute (DLI) of the University of Lagos, Lagos, Nigeria.

\section{References}

[1] AFFENDY, L.S., Paris, I.H.M., Mustapha, N., Nasir Sulaiman, Md. And Muda, Z. 2010. Ranking of influence Factors in predicting students' performance. Information Technology Journal, 9:832-837.

[2] ALDOUS, C., Leeder, S., Price, J., Sefton, A. and Tuebner, J. 1997. A selection of tests for Australian graduate-entry medical schools. Medical Journal of Australia. 166:247-250.

[3] BLACKMAN, Ian and Darmawan, I. Gusti Ngurah. 2004. Graduate-Entry Medical Student variables that Predict Academic and Clinical Achievement: International Education Journal, Vol.4 (No.4) 2004. Educational Research Conference 2003. Special Issue http://iej.cjb; http://iej.net.

[4] CHANSARKAR, B.A., and Michaeloudis, A. 2004. Student profiles and factors affecting performance. International Journal of Mathematics, Education Science and Technology, Volume 32(1) 97-104.

[5] CRAIG, P.L., Gordon, J.J., Clark, R.M. and Langendy, K.V. 2004. Medical Education, Volume 38. Issue 11, pp. 1164-1168. www.mededuc.com

[6] GOLDING, P. and Donalson, O. 2006. Predicting academic performance. Proceedings of the $36^{\text {th }}$ ASEE/IEEE Frontiers in Education Conference TID-21, October 28-31, San Diego, CA, pp. 1-6.

[7] GRACIA, L. and Jenkins, E. 2003. A quantitative exploration of students' performance on an undergraduate accounting programme of study. Accounting Education, 12(1) 15-32.

[8] HUFF, K. and Fang, D. 1999. When are students most at risk of encountering academic difficulty? A study of the 1992 matriculants to US Medical Schools. Academic Medicine 74, 454-460.

[9] JAMES, D. and Chilvers, C. 2001. Academic and non-academic predictors of success on the Nottingham undergraduate medical course. 1970-1995. Medical Education 35:1056-1064.

[10] JOSSEY, Bass. 1977. Selective admissions in higher education. Carnegie Foundation for the Advancement of Teaching.

[11] KAY, L., Pearson, S. and Rolfe, I. 2002. The influence of admission variables on first year medical school performance. A study from Newcastle University, Australia. Medical Education. 36:154-159.

[12] KIM, Minkang and Jae II Lee. 2007. Variables Predicting Student's First Semester Achievement in a Graduate-Entry Dental School in Korea. Journal of Dental Education. 74(4): 550-556. 
[13] KOOI, Lew Teik and Teoh Ai Ping. 2007. Factors Influencing Student's Performance in WAWASAN Open University: Does previous education level, age group and course load matter?

[14] KUMAR, Vipan, Kumar, Naresh and Gupta, Nitin. 2008. Performance in Science at Secondary/Higher Secondary Level. India, Science and Technology. http://www.nistads.res.in/india.snt.2008/t1human resources/t1 hr4.htm.

[15] PATRICIA, L.H., Chen Ching-Huei, Huang Su-Hua, Chiang Chen-Ting, Jen Fen-Lan and Warden Leslie. 2006. Factors affecting High School Students' Academic Motivation in Taiwan. Asia Pacific Journal of Education, Vol.26 (2): 189-207.

[16] FOLFE, I.S., Pearson, D., Poivis, and Smith, A. 1995. Time for a review of admission to Medical School? Lancet, 346:1329-1333.

[17] SYED, Tahir Hajazi and Roza, Naqvi. 2006. Factors Affecting Students' Programme. A case of Private Colleges. Bangladesh eJournal of Sociology, Volume 3(1) 